\title{
Biomedical applications of polyurethane materials and coatings
}

\author{
J. Joseph, ${ }^{1,2}$ R. M. Patel, ${ }^{1}$ A. Wenham ${ }^{1}$ and J. R. Smith ${ }^{1, *}$ \\ ${ }^{1}$ School of Pharmacy and Biomedical Sciences, University of Portsmouth, St Michael's Building, \\ White Swan Road, Portsmouth PO1 2DT, UK \\ ${ }^{2}$ Teledyne-Impulse-PDM, 4-6 Alton Business Centre, Omega Park, Alton, Hampshire GU34 2YU \\ *Corresponding author: james.smith@ port.ac.uk
}

\begin{abstract}
Polyurethanes (PUs), formed by the reaction of diisocyanates with polyols (or equivalent) in the presence of a catalyst, have a wide variety of industrial uses. Much recent attention has focused on their biomedical applications, owing to their biocompatibility, biodegradability and tailorable chemical and physical forms. Examples of such application areas include antibacterial surfaces and catheters, drug delivery vehicles, stents, surgical dressings/pressure sensitive adhesives, tissue engineering scaffolds and electrospinning, nerve generation, cardiac patches and PU coatings for breast implants. Following a brief introduction to PUs, this review surveys selected articles, mostly from 2014 to 2017, that highlight this diverse range of biomedical applications offered by PU materials and coatings.
\end{abstract}

Keywords: Polyurethane, polymers, coatings, biomedical, medical, applications, drug delivery, vascular grafts, tissue engineering.

$\begin{array}{ll}\text { Abbreviations } & \\ \text { BD } & 1,4^{\prime} \text {-Butanediol } \\ \text { ECM } & \text { Extra cellular matrix } \\ \text { HMDI } & 4,4^{\prime} \text {-Dicyclohexylmethane diisocyanate } \\ \text { HDI } & 1,6 \text {-Hexamethylene diisocyanate } \\ \text { IPDI } & \text { Isophorone diisocyanate } \\ \text { MDI } & 4,4^{\prime} \text {-Methylene diphenyl diisocyanate } \\ \text { PCL } & \text { Polycaprolactone } \\ \text { PECUU } & \text { Poly(ester carbonate urethane)urea } \\ \text { PEG } & \text { Polyethylene glycol } \\ \text { PEP } & \text { Polyester polyols } \\ \text { PLA } & \text { Polylactide } \\ \text { PLGA } & \text { Polylactic-co-glycolic acid } \\ \text { PPG } & \text { Polypropylene glycol } \\ \text { PTMEG } & \text { Polytetramethylene ether glycol } \\ \text { PU } & \text { Polyurethane } \\ \text { PUS } & \text { PurSil®AL20 } \\ \text { REACH } & \text { Registration, Evaluation, Authorisation and Restriction of Chemicals } \\ \text { RoHS } & \text { Restriction of the use of certain Hazardous Substances } \\ \text { TDI } & \text { Toluene diisocyanate } \\ \text { TPU } & \text { Thermoplastic polyurethane }\end{array}$




\section{Introduction}

Polyurethanes (PUs) were invented by Professor Dr Otto Bayer in the 1930s, building on a reaction discovered in 1849 that alcohols can react with isocyanates to produce urethane (carbamate) groups. ${ }^{1}$ By the 1950s, PUs were finding a diverse range of applications, including coatings, adhesives, rigid foams, and elastomers. ${ }^{2}$ Today, PUs are one of the most versatile class of materials, ${ }^{3}$ finding an everincreasing range of applications in many manufacturing sectors; annual production in 2015 had reached over 18 million tons. ${ }^{4}$

Coatings form a significant proportion of PU's applications (perhaps 10\%). Examples include PU paints (for steel, concrete, wood and other surfaces), ${ }^{5,6}$ and coatings for automotive interiors, ${ }^{7}$ automotive acid-rain etching-resistant topcoats and clearcoats, ${ }^{8}$ aircraft,,${ }^{8}$ industrial machinery, ${ }^{9}$ adhesives, ${ }^{10}$ marine applications ${ }^{11,12}$ and many others. PU is applied as coatings using various methodologies, such aspowder coatings, dip-coating, spray, roller, curtain-coater or electrostatic application. ${ }^{8,13}$ Reasons for the use of PU coatings include high-performance characteristics, such as durable finish, flexibility, toughness, strength, abrasion, corrosion, chemical and stain resistance, good light stability when aliphatic isocyanates are used, high gloss with exceptional UV protection characteristics and good low temperature properties. ${ }^{5,6,8,14}$ The latter factor is an important reason for the use of PU coatings on plastic substrates, including topcoats to epoxy surfaces. ${ }^{12}$

In an excellent review published in 1999, Zdrahala \& Zdrahala describe the historical development of the science and application of PUs in the biomedical arena. ${ }^{15}$ These authors state that it was perhaps a paper appearing in Science in 1967 describing the use of a "medical-grade" elastomer ${ }^{16}$ that brought PUs for biomedical applications into the spotlight.

This article reviews a number of papers, mostly from 2014-2017, that highlight the diverse range of biomedical applications offered by PUs, following an introduction into their chemistry and properties.

\section{The chemistry of PUs}

PUs are produced by the addition polymerisation of an isocyanate (generally a diisocyanate), derived from crude oil, and a polyol (polyether or polyester, or similar), often in the presence of a catalyst and a chain extender to form the desired polymer (Fig. 1). ${ }^{17}$ Additives, such as fillers, degassing agents, moisture scavengers and pigments, are also often included.

\section{Diisocyanates}

Diisocyanates are isocyanates containing two $-\mathrm{N}=\mathrm{C}=\mathrm{O}(\mathrm{NCO})$ groups per molecule. ${ }^{17,18}$ These can be aliphatic (e.g., 1,6-hexamethylene diisocyanate, HDI), cycloaliphatic (e.g., isophorone diisocyanate, IPDI), dicycloaliphatic (e.g., 4,4'-dicyclohexylmethane diisocyanate, HMDI), polycyclic or aromatic (e.g., toluene diisocyanate, TDI, or more commonly, 4,4'-methylene diphenyl diisocyanate, MDI). The isocyanate reactivity is governed by the positive character of the NCO carbon atom, which is susceptible to attack by nucleophiles, and oxygen and nitrogen by electrophiles. ${ }^{18}$ In aromatic diisocyanates, the negative charge becomes delocalised onto the ring and hence these molecules are more reactive than their aliphatic counterparts. ${ }^{8}$ The choice of isocyanate for PU production is governed by the properties required for end-use applications. To prepare rigid PUs, aromatic isocyanates are chosen, however, PU derived from these isocyanates show lower oxidative and ultraviolet stabilities than aliphatic diisocyanates, which are also more expensive. ${ }^{18}$ A key property of isocyanates is their NCO content, this typically being $23-48 \% .^{19}$ 

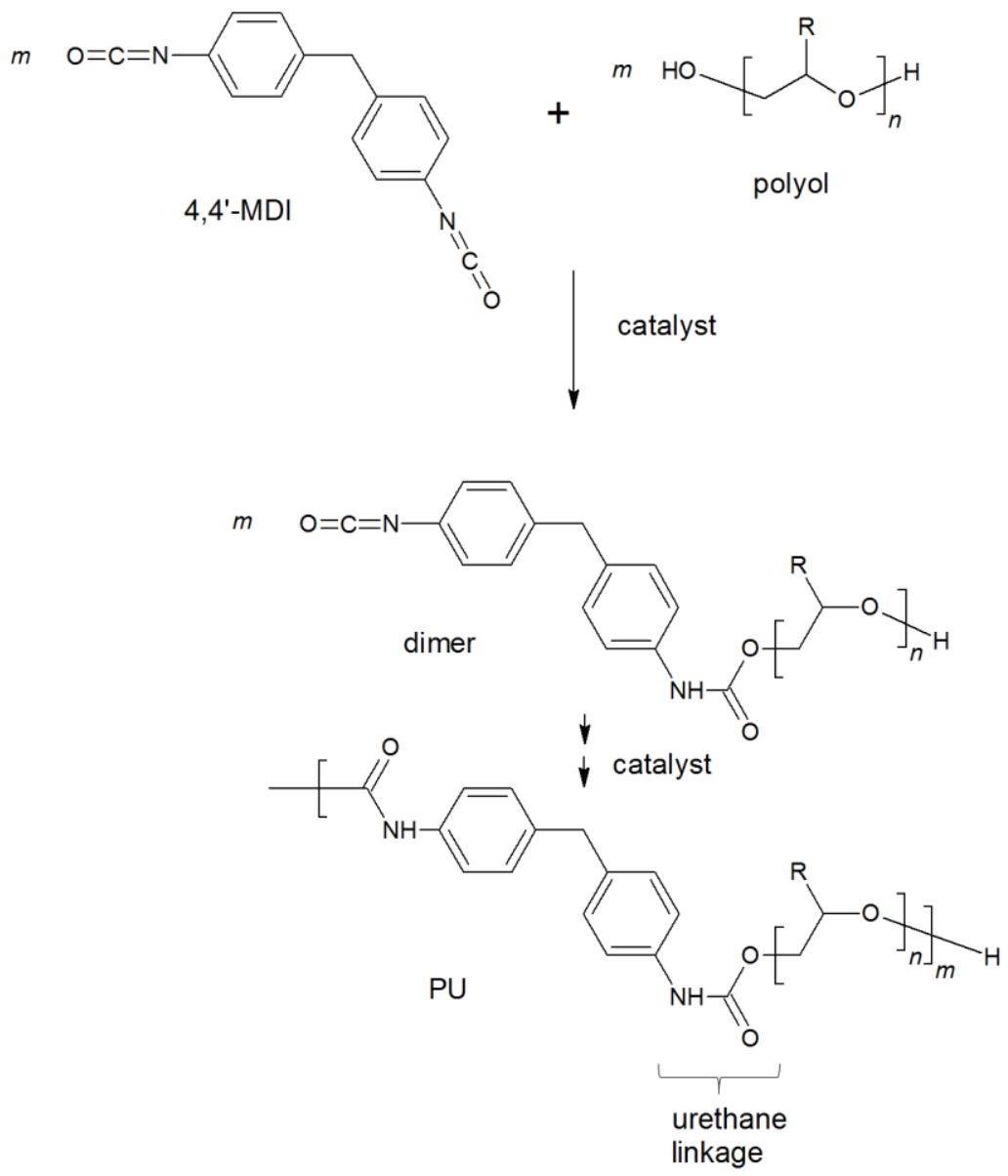

Fig. 1. Reaction of a common diisocyanate (MDI) with a polyol to form a PU, with the idealised structure, dimer and urethane linkage shown.

\section{Polyols}

The polyol component usually comprises of polyesters, polyester polyols (PEP), polycaprolactones (PCLs), polycarbonates or polyethers. Polyesters, introduced between 1937 and 1956, have better solvent, abrasion and cut-resistance, although are susceptible to hydrolytic degradation. ${ }^{20}$ Polyethers, introduced in 1956, are more commonly used, although tend to suffer from oxidative degradation. Three common types are polyethers are used: polypropylene glycols (PPGs), polyethylene glycols (PEGs) and polytetramethylene ether glycol (PTMEG), the latter of which is made from polymerisation of tetrahydrofuran (THF) and is used in high-performance coatings and in wetting and elastomer applications. PUs produced from PTMEGs tend to have the best physical, higher resilience, hydrolytic stability and dynamic properties. ${ }^{21}$ There are more than 500 commerically available polyols and with a much reduced set of available isocyanates, it is the polyols that fundamentally determine the final PU properties. ${ }^{22}$

Branching in PEPs also dramatically change PU properties: high-branched PEPs produce rigid PUs with good chemical and thermal resistance, whereas, less branched PEPs produce flexible PUs with inferior chemical resistance. ${ }^{18}$ Flexible PUs also results from using polyols with high molecular mass and vice versa. ${ }^{18}$ 


\section{Chain extenders}

Chain extenders are usually short-chain diols added during the PU polymerisation process that further modify the properties of the resultant PU. ${ }^{23}$ A typical example is 1,4-butanediol (BD), and this has been shown to produce hard segments within the resultant PU. Other difunctional, low molecular mass diols, cyclohexane dimethanol, diamines, hydroxylamines (diethanolamine and triethanolamine) are also sometimes used as chain extenders. Glycerol is another commonly used extender, with the advantage of producing a crosslinked structure owing to it having three $\mathrm{OH}$ groups per molecule; this increases thermal stability in the PU.

\section{PU catalysts}

PUs can be synthesised in the presence or absence of a catalyst, although the former is more common. Catalysts play a key role in controlling the reaction kinetics, reducing curing temperatures and durations, and are very often responsible for the preferred polymerisation reaction taking place. ${ }^{24}$ Catalysts used for synthesising PUs have included bismuth, butyl tin trichloride, titanium tetrachloride, ferric chloride, antimony trichloride, cadmium nitrate, cobalt benzoate, aluminium oleate, diphenyl mercury, zinc naphthenate, zirconium naphthenate and molybdenum. ${ }^{25}$ Obviously, a number of these are toxic and have now been withdrawn under legislation placed on industry, such as that of $\mathrm{RoHS}^{26}$ and $\mathrm{REACH}^{27}$ regulations. Tin catalysts are often now used for manufacturing prepolymers and amines (strong bases, e.g., diaminobicyclooctane, DABCO) for the reaction of polyols and isocyanates. ${ }^{19}$

\section{PU properties}

PUs are made up of alternating soft and hard segments (Fig. 2a) ${ }^{28}$ The soft segments are dependent on the long-chain diol providing elasticity and low temperature resistance to the polymer..$^{20,28-30}$ The hard segments are thought to be due to the reaction between the chain extender, often a low molecular weight diol, and the diisocyanate producing hydrogen bonding involving urethane links and provides the extra strength. ${ }^{28,30,31}$ These hard segments are responsible for crystalline regions, modulus, upperuse temperature, tear strength and hardness of PU. ${ }^{29}$

Change in the chemical composition (monomer/raw materials, functional group number), ratio of hard-to-soft segments or molecular mass result in a range of different polymer properties and hardnesses ${ }^{30}$ For example, urethane groups have high polarity, hence, a larger density of urethane groups increases polarity producing a rigid, hard PU product at room temperature.

While most PUs are not thermosets (cannot be processed, melted and then re-processed), thermoplastic PUs (TPUs) are readily available. In these polymers, there is a strong attraction between the hard segments due to the high polarity, resulting in a high degree of aggregation and order in this phase, displayed as crystalline or apparent crystalline areas, often referred to as fixed phase. ${ }^{31}$ The hard segments are partially separated from the soft segments: this is often referred to as phase separation (Fig. 2b) ${ }^{32}$ The degree of phase separation and its effect depends on the difference between the molecular mass and polarity of the two segments. This is because, as described by Michael Szyycher ${ }^{29}$ dipole-dipole interactions and hydrogen bonding provide a pseudo-cross-linked network structure between linear PU chains creating a polymer with the physical characteristics and mechanical behaviour of a covalently crosslinked network. Hydrogen bonds can also form between $\mathrm{N}$ $-\mathrm{H}$ and $\mathrm{C}=\mathrm{O}$ groups, either within hard segments, soft segments or bridging the two. ${ }^{33}$ Hydrogen bonding in the hard phase between the urethane bonds creates a physical crosslinking point, preventing polymer deformation due to chain slippage. Three-dimensional crosslinking can be achieved when multifunctional components such as triisocyanates or branched hydroxyl polyols are used. ${ }^{34}$ The percentage crystallinity can be anywhere in the region of $0-13 \%$, with a fully crystalline PU having a density of $1.322 \mathrm{~g} \mathrm{~cm}^{-3}$ at $20^{\circ} \mathrm{C}$. 


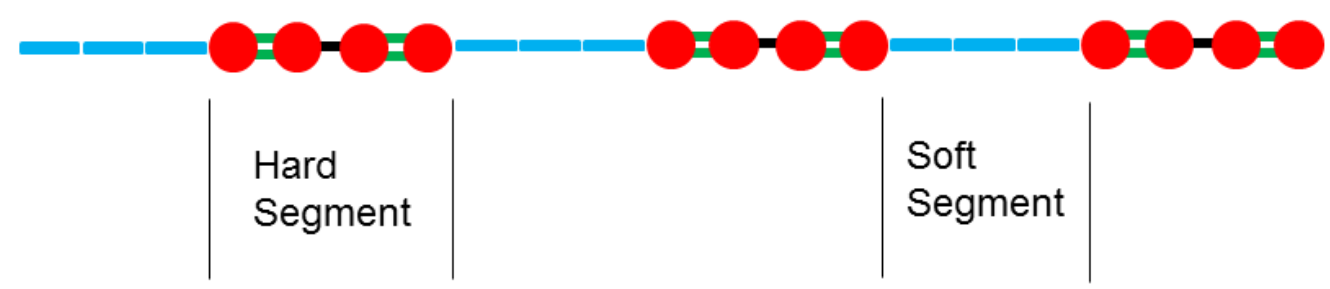

(a)

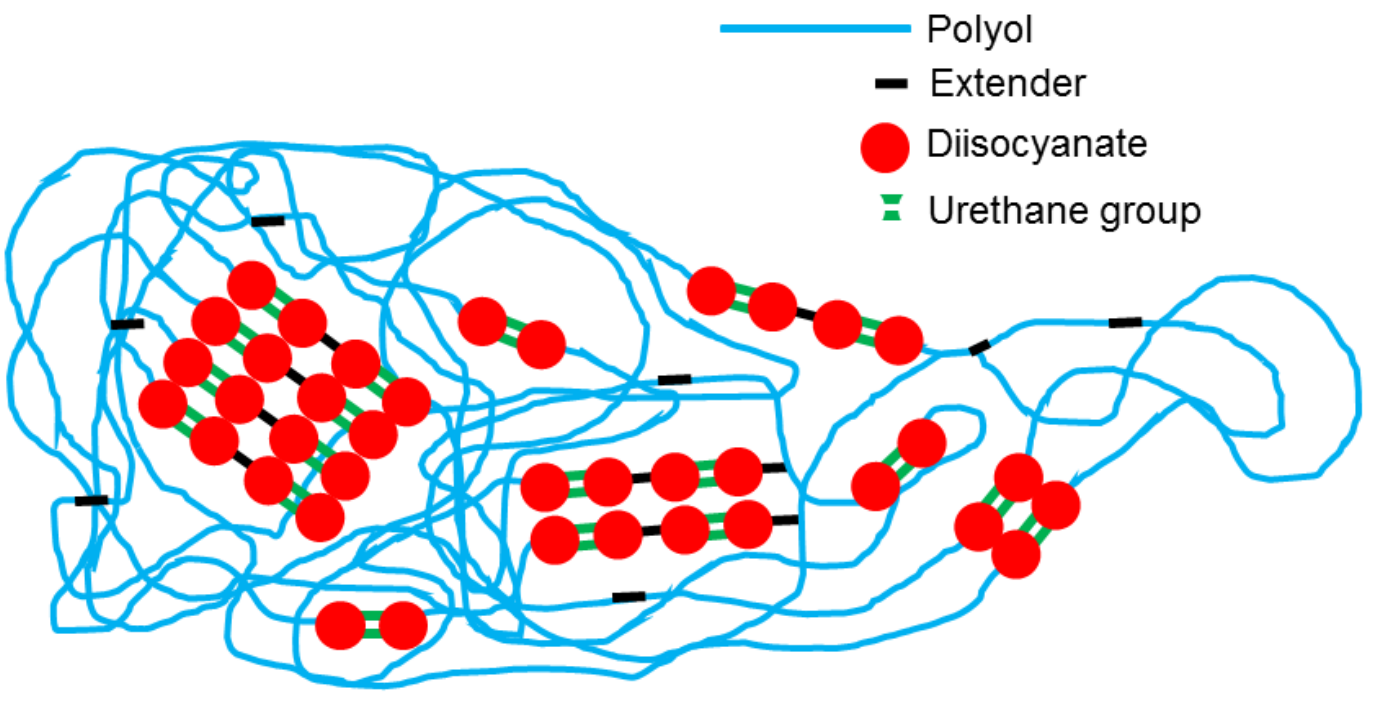

Fig. 2. Idealised structure of PU depicting the origin of formation of hard and soft segments (a) from chain alignment of isocyanates and presence of non-aligned, long-chained polyols (b), respectively.

Numerous factors affect the degree of phase separation, such as polarity of functional groups, molecular mass, molecular mass distribution, crosslinking density, chemical structure of PU chains, size of the hard and soft segments and even the technique used to shape the final product. ${ }^{34}$

\section{Biomedical applications of PU}

PUs offer one of the most diverse classes of materials. ${ }^{18}$ Their uses span from flexible foam in upholstered furniture, rigid foam in insulation of walls and roofs, thermoplastic PU used in medical devices, to coatings, elastomers, adhesives and sealants used on floors and automotive interiors. ${ }^{18}$ PUs are unique, offering the elasticity of rubber combined with the toughness and durability of metal. These polymers are available over an extremely broad hardness range (eraser-soft to bowling-ballhard). ${ }^{16}$ Vast improvements in down-time, maintenance time and costs have resulted from PU replacing tranditionally used materials. ${ }^{35}$ The remainder of this review highlights recent (2014-2017) reported biomedical uses of PU coatings and materials.

PUs, unlike many other synthetic and natural biodegradable polymers, have mechanical and physical properties comparable to natural tissue. ${ }^{36}$ This, matched with low platelet adhesion and in vitro protein adsorption allows many uses of PU in the biomedical industry. ${ }^{34}$ Critically, consideration of the biodegradation of PUs, as with other biomaterials, needs to be considered. Tailoring these properties, in the case of PUs, can be easily achieved through variation of the chemical composition, ratio of hard-to-soft segments and the molecular mass. Generally, the rate of PU biodegradation is mainly dependent on the soft segment structure, which is controlled by the polyol chemistry. ${ }^{36}$ This is in keeping with the observation that PUs with amorphous structures degrade more rapidly than those with semi-crystalline segments, since they allow permeation of water through the amorphous regions. 
PPGs, PEGs, PCLs and glycolic acid are common polyols used in biodegradable PUs. Nontoxic degradation products are one of the main attractions in PEGs as well as hydrophilicity, solubility in water and organic solvents and absence of antigenicity and immunogenicity. PCLs also produce nontoxic degradation products, although are often more hydrophobic and so reduce degradation rates. Increasing this property can be affected through the introduction of hydrolysable chain extenders into the hard segments. BD, 1,2-ethanediamine and 1,2-ethanediol are often used as chain extenders. Both aromatic and aliphatic diisocyanates are used in making biodegradable PU systems, although the former (e.g., TDI and MDI) have been found to degrade into toxic by-products and are being replaced with aliphatic diisocyanates (e.g., IPDI and HDI).

Some specific and recent biomedical applications of PU are detailed below.

\section{Antibacterial surfaces and catheters}

Jiang et al. used novel amphiphilic poly(dimethylsiloxane)-based PU networks tethered with carboxybetaine to achieve an antibacterial efficiency of $97.7 \%$ and possessed anti-adhesive properties, demonstrating great potential for biomedical devices and in marine applications. ${ }^{20}$ Substitution of the polyol with chitosan, a biocompatible polysaccharide isolated from crustaceans and fungi, led to a PU, adsorbed onto sterilised discs, that showed improved E. coli inhibition compared to chitosan alone. ${ }^{37}$ Chitosan and heparin (the latter having a high negative charge that repels negatively charged bacteria) have been immobilised onto the surface of PU in a stepwise process to produce an antibacterial layer resistant to Staphylococcus aureus, S. epidermidis, E. coli and Pseudomonas aeruginosa. ${ }^{38} \mathrm{Cu}$ and $\mathrm{Ag}$ nanoparticles have been incorporated into the polyol component (PTMEG 1000) and then reacted with the isocyanate (MDI) with a BD extender; the resultant PUs showed no toxicological issues and exhibited the desired antimicrobial activity suitable for medical applications. ${ }^{39}$ Zanini et al. coated PU catheters with 3-(trimethoxysilyl)-propyldimethyloctadecylammonium chloride in a multistep process that involved a vapor phase plasma-induced graft polymerisation of acrylic acid; ${ }^{40}$ the coated catheters exhibited antimicrobial activity against $E$. coli (Fig. 3). A review of recent advances in antimicrobial coatings for urinary catheters appeared in $2017 ;{ }^{41}$ the authors list the advantages and disadvantages of various polymers, including PU, advantages of which include toughness, biocompatibility, haemocompatibility and ease of processing. The review describes a number of coated PU materials with antibacterial properties, such as a salicylic acid-releasing PU coating ${ }^{42}$ with resistance against $P$. aeruginosa and E. coli, and an $N$-halamine generating coating grafted onto PU which could be regenerated for long-term use. ${ }^{43}$

A

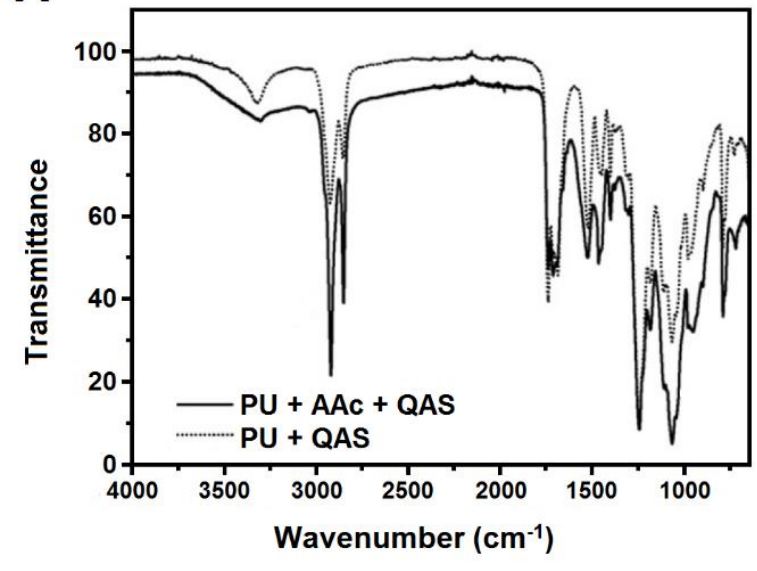

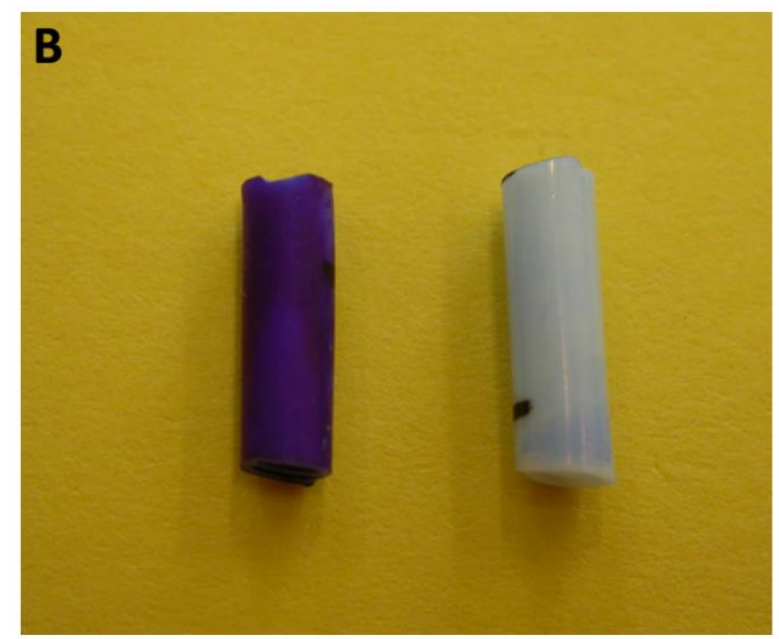

Fig. 3. FTIR (attenuated total reflectance) and photographs of acrylic acid modified (left picture) and untreated PU catheter after silanisation and treatment with bromophenol blue to confirm the presence of the acrylic acid coating. This coating exhibited in vitro antimicrobial activity against E. coli. ${ }^{40}$ 


\section{Drug delivery vehicles}

The chemotherapy drug gefitinib has been embedded between PU support and top layers using spray coating to form a drug-eluting stent for bronchotracheal cancer; ${ }^{44}$ when the drug was embedded as crystals, release was recorded for 7-21 days, but when embedded into poly(lactic-co-glycolic acid) (PLGA) microspheres, a sustained release $>6$ months was noted (Fig. 4). Solanki and Thakore have modified PU with acid chain extenders to impart swelling controlled drug release properties and PU $\mathrm{pH}$-responsive characteristics; release of felodipine (a model drug) was faster at $\mathrm{pH} 7.4$ than gastric $\mathrm{pH}$ 1.2, offering targeted delivery for the colon. ${ }^{45}$ PU-based (polyesterurethane) nanoparticles, containing indomethacine (an anti-inflammatory drug) have been embedded in a surface polymeric (gelatin) layer on a composite shell scaffold (bioactive glass/hydroxyapatite); ${ }^{46}$ a sustained drug release was observed and the biocompatibility was not compromised. Campiñez et al. synthesised new biodegradable PUs, containing disulphide bonds, and studied their ability to be used as sustained release excipients for delivery to the colon. ${ }^{47}$

The stability of PurSil®AL20 (PUS), a copolymer of HMDI, BD, poly(tetramethylene oxide) (PTMO) and poly(dimethylsiloxane) (PDMS), for use as a vehicle for docetaxel delivery through an oesophageal drug eluting stent (DES) was investigated by Shaikh et al. ${ }^{48}$ solid-state behaviour of docetaxel and polymer microstructure were found to affect drug release. Da Silver et al. report the successful incorporation or borage oil (containing essential fatty acids for wound healing) into and its release from PU foam wound dressings; the authors also review many other drugs that have been incorporated into such dressings, e.g., analgesics, cicatrizing agents, antibiotics and anti-cancer drugs. ${ }^{49}$

Electrospun PU-dextran nanofibre mats have been loaded with estradiol (the most bioactive endogenous estrogen) to improve cutaneous wound repair in post-menopausal women ${ }^{50}$ the electrospinning process directly blends the PU and dextran polymers to obtain the optimum physical and biological properties of the fibres. Electrospinning was also used to make a nanofibre composite PU-Eudragit acrylic polymer mat in which the $\mathrm{pH}$ dependent release of paclitaxel was investigated; ${ }^{51}$ the acrylic polymer allowed release of the drug in the duodenum (mean $\mathrm{pH}$ 5.4). Smart sensitive polymers, designed to change properties based of environmental conditions ( $\mathrm{pH}$ sensitive in this case), have been prepared from PU-N,N-diethylaminoethyl methacrylate hybrids, with rhodamine $6 \mathrm{G}$ added as a model drug; ${ }^{52}$ loading methods and release mechanisms were discussed. Graphene nanoparticles have been dispersed into incorporated into PTMEG and reacted with HMDI, with BD extender, to produce a PU with greater toughness and storage modulus than without the inclusion; ${ }^{53}$ controlled release of an incorporated drug (tetracycline hydrochloride, an antibiotic) was also more sustained than with PU alone that had a burst release.

\section{Stents}

PU stents comprising an Auxetic (rotating-squares) geometry (to reduce migration/misplacement) for use in palliative treatment of squamous cell carcinoma of the oesophagus have been manufactured using a variety of techniques; laser-cutting of vacuum casted steamless stents were favoured.$^{54}$ Aguilar et al. describe a thermoresponsive matrix incorporating nanofibres in PU for a non-vascular nitinol stent alternating that uses an alternating magnetic field for hyperthermia therapy; ${ }^{55} 5$-fluorouracil and/or paclitaxel were simultaneously released. Polyethyleneimine (PEI) brushes have been grafted onto PU ureteral stents to help prevent host tissue inflammation and blockage, ${ }^{56}$ further alkylation of the brushes led to enhanced antibacterial activity. PU stents are being used in infants and children with Kawasaki disease, a multisystem inflammatory disease that is the most common cause of acquired heart disease in children ${ }^{57}$ the thick $(90 \mu \mathrm{m})$ PU membrane electrospun around an Orsiro stent had the most desirable stretching properties. 

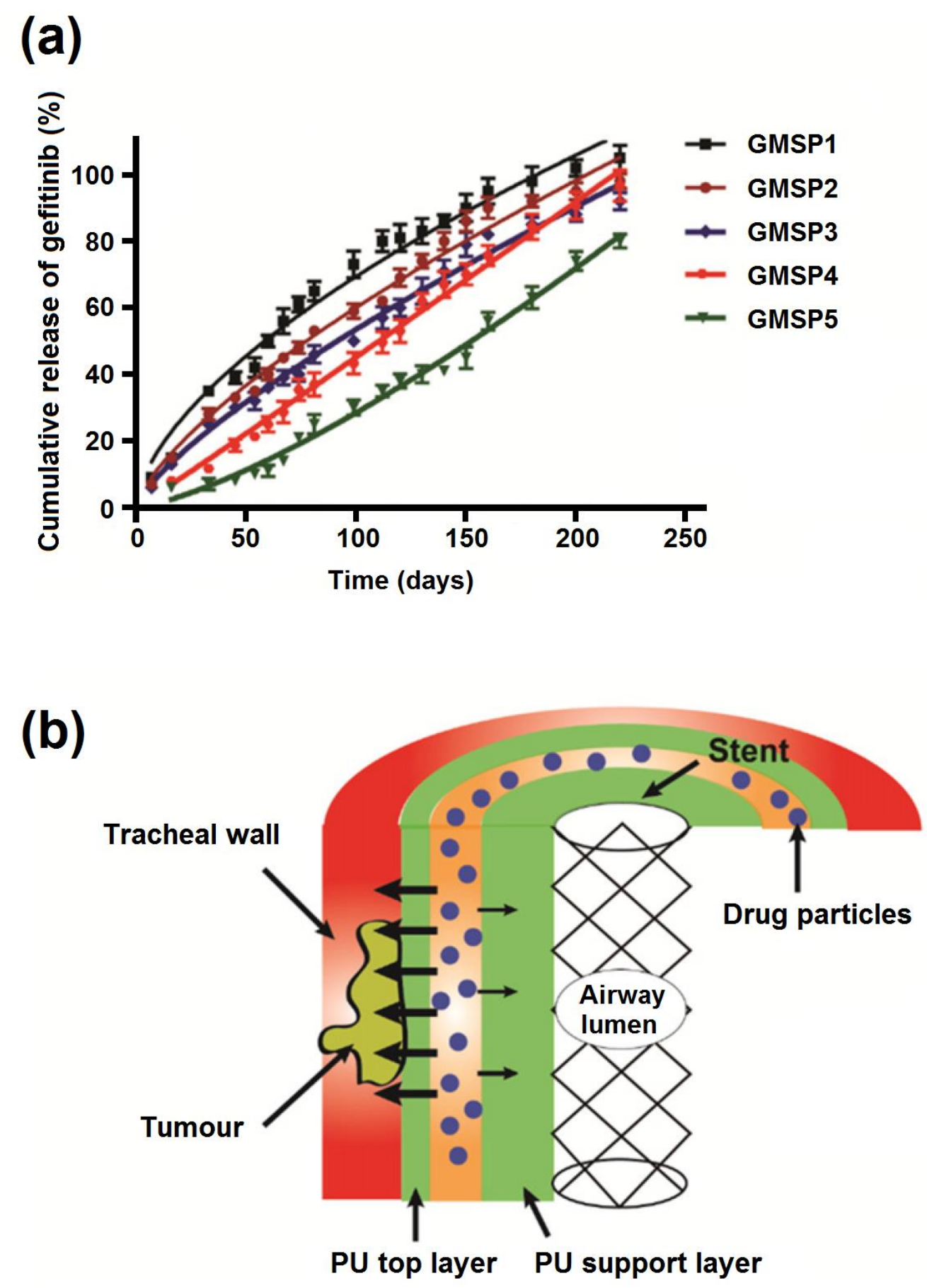

Fig. 4. (a) Release of tumour suppressing drug gefitinib from PU constructs loaded with gefitinibPLGA microspheres; (b) schematic of bronchotracheal stent to provide long-term release of this drug. ${ }^{44}$

\section{Surgical dressings/pressure sensitive adhesives}

PUs have superior properties to many other polymers for use as pressure sensitive adhesives (PSAs); these materials provide good adhesion to substrates, such as skin, with only slight finger pressure and hence are commonly used for surgical dressings. ${ }^{58}$ Breathability and adhesion strength in these materials have been improved using different crosslinkers by Singh et al. ${ }^{58} \mathrm{PU}$-dressing foams offer excellent water absorption, optical mechanical properties and cost effective, but have low bioactivity 
and poor healing capability; incorporation of bioactive silica nanoparticles during the sol-gel process improved wound-closure rates and accelerated collagen and elastin fibre regeneration. ${ }^{59}$ Morgado et al. also reported a modified crosslinked PU hydrogel, which absorbed large quantities of water without dissolving. This property is useful for wound healing dressings where an asymmetric membrane made of a PEG polyol prevents the rapid dehydration of the wound surface and penetration of bacteria. Platelets are attracted to this layer due to its hydrophilic character, which generates the coagulation cascade. ${ }^{60}$

\section{Tissue engineering scaffolds and electrospinning}

Electrospinning has been used to combine PU with the propolis (a resinous substance, with a variety of medical properties, produced by bees) to make tissue scaffolds; ${ }^{61}$ i.e., a material that mimics the extra cellular matrix (ECM), offering temporary support for cell growth, migration and tissue regeneration (Fig. 5). The resultant mats exhibited antibacterial activity and enhanced cytocompatibility/cell viability, showing promise for use in wound dressings and skin tissue engineering. A review comparing electrospinning and microfluidic spinning approaches to producing micro- and nanofibres appeared in 2017; ${ }^{62}$ the paper reports PU fibres being used in tissue engineering of dense tissues, and ECM generation of human ligament fibroblasts on a PU nanofibre matrix. Segmented PUs (SPUs), based on PEG, poly(L-lactide) and poly(trimethylene carbonate) blocks and using an aliphatic diisocyanate, were electrospun into fibrous scaffolds; ${ }^{63}$ novel biodegradable elastomeric highly porous matrices showing promise for soft tissue engineering were produced. In a 2015 review by Janik and Marzec, the use, methods of fabrications, relative merits and latest developments of PU foam systems for scaffolds are presented. ${ }^{64}$ Cardiac cell proliferation on PU nanofibrous mats produced by blow spinning was found to be superior to that of polystyrene and hence could form a better in vitro model for the study of cardiac drugs than the current use of polystyrene. ${ }^{65}$

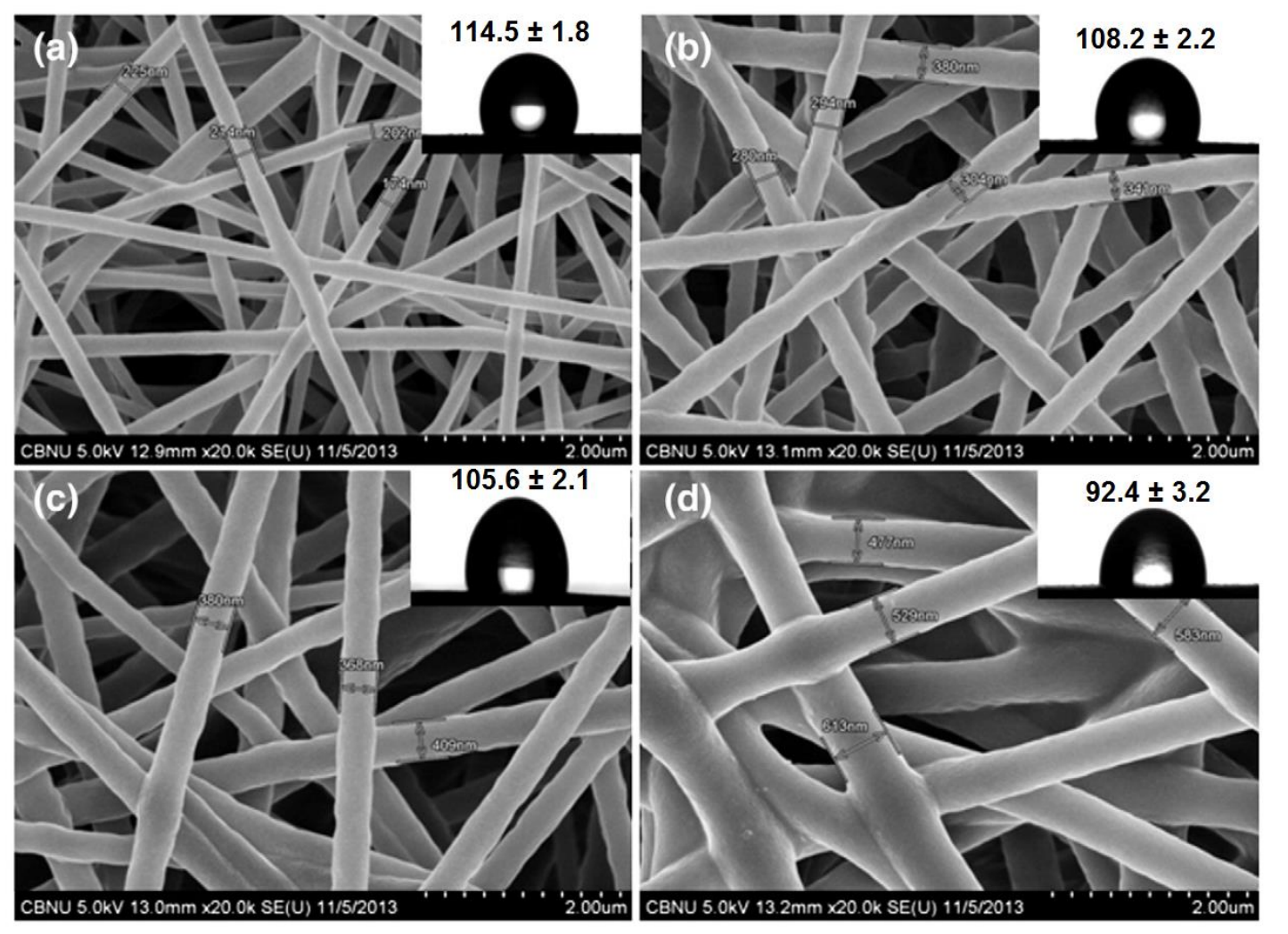

Fig. 5. SEM (field-emission) images of PU fibres obtained from (a) 0, (b) 5, (c) 10 and (d) $30 \mathrm{wt} \%$ propolis-containing PU solution. Inserts show corresponding water contact angles. ${ }^{61}$ 


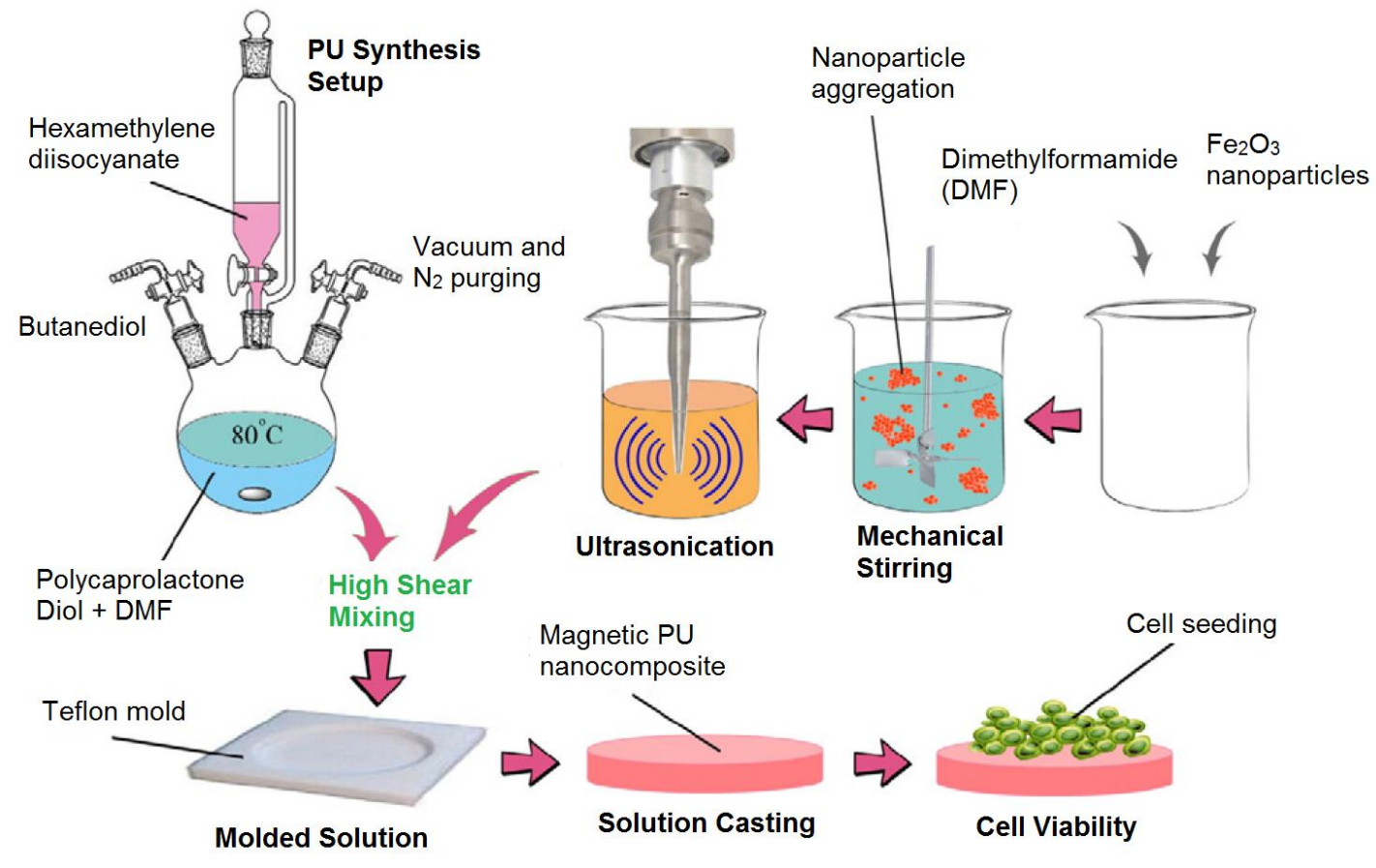

Fig. 6. Schematic showing process of thermoplastic PU nanocomposite fabrication for potential cell therapy and tissue engineering applications. ${ }^{66}$

Shahrousvand et al. included iron oxide nanoparticles into PU for tissue engineering applications (Fig. $6) ;{ }^{66}$ a variety of techniques were used to characterise the films produced, including atomic force microscopy (AFM) to measure surface roughness.

PU modified with ascorbic acid (vitamin $\mathrm{C}$ ) has been investigated as a material for regenerative medicine of soft tissue, owing to the known wide influence of the inclusion on tissue regeneration; ${ }^{67}$ haemocompatibility tests were successful and the films were sensitive to $S$. aureus, $P$. aeruginosa and E. coli.

Marzec et al. recently produced a review of recent developments on the use of PU in bone tissue engineering; ${ }^{68}$ PUs are particularly attractive for such applications owing to their ability to calcify, support cell adhesion and proliferation of human osteoblast cells, ${ }^{69}$ in addition to their non-toxic and tailorable mechanical properties.

\section{Nerve regeneration}

A highly tunable conductive polymer (aniline pentamer) with PU has been constructed that enhances myelin gene expression and neurotrophin secretion necessary for peripheral nerve regeneration. ${ }^{70}$ Polymer mats made from a PU-polylactide (PLA) blend for connecting broken nerve tracks using olfactory-bulb glial cells and mesenchymal stem cells were studied by Grzesiak et al.; ${ }^{71}$ glial cells on pure PU exhibited altered morphology, but the blended polymer showed optimal properties (Fig. 7). Using a 3d-printing system, Hsieh et al. successfully embedded neural stem cells into biodegradable PU gels: $;{ }^{72}$ these could then be injected into zebrafish to restore an impaired nervous system.

\section{Cardiac patches}

Reduced ventricular contractile function often results when scar tissue replaces cardiomyocytes following myocardial infarction (MI). ${ }^{73}$ These cells have been cultured onto nanocomposite scaffolds 
of Au nanotubes/nanowires incorporated into biodegradable, nano-porous $\mathrm{PU} ;{ }^{73}$ electrical stimulation was also successful in producing cell-cell interaction, as was key myocardium gene expression. D'Amore et al. used a bilayer patch consisting of a cardiac ECM-enriched layer containing sparse, microporous, biodegradable poly(ester carbonate urethane)urea, PECUU) and an upper microporous PECUU layer; ${ }^{74}$ reduced scar formation, reduced ventricle thinning and a promotion in angiogenesis were observed.

\section{PU coatings for breast implants}

PU foam coatings for silicone breast implants were first developed in the 1970s as a method of reducing capsular contracture. ${ }^{75,76}$ The PU coating is designed to break down and becomes part of the capsule and prevents alignment of myofibroblast cells, interrupting the strength required for capsular contracture. ${ }^{77,78}$ A link between PU and the carcinogen 2,4-toluenediamine (TDA) was made in $1991,{ }^{79}$ however, which led to a ban on such coated implants in the US and UK. A systematic review by Duxbury \& Harvey in 2016 concluded that PU implants should be considered a safe alternative to textured silicone implants. ${ }^{80}$

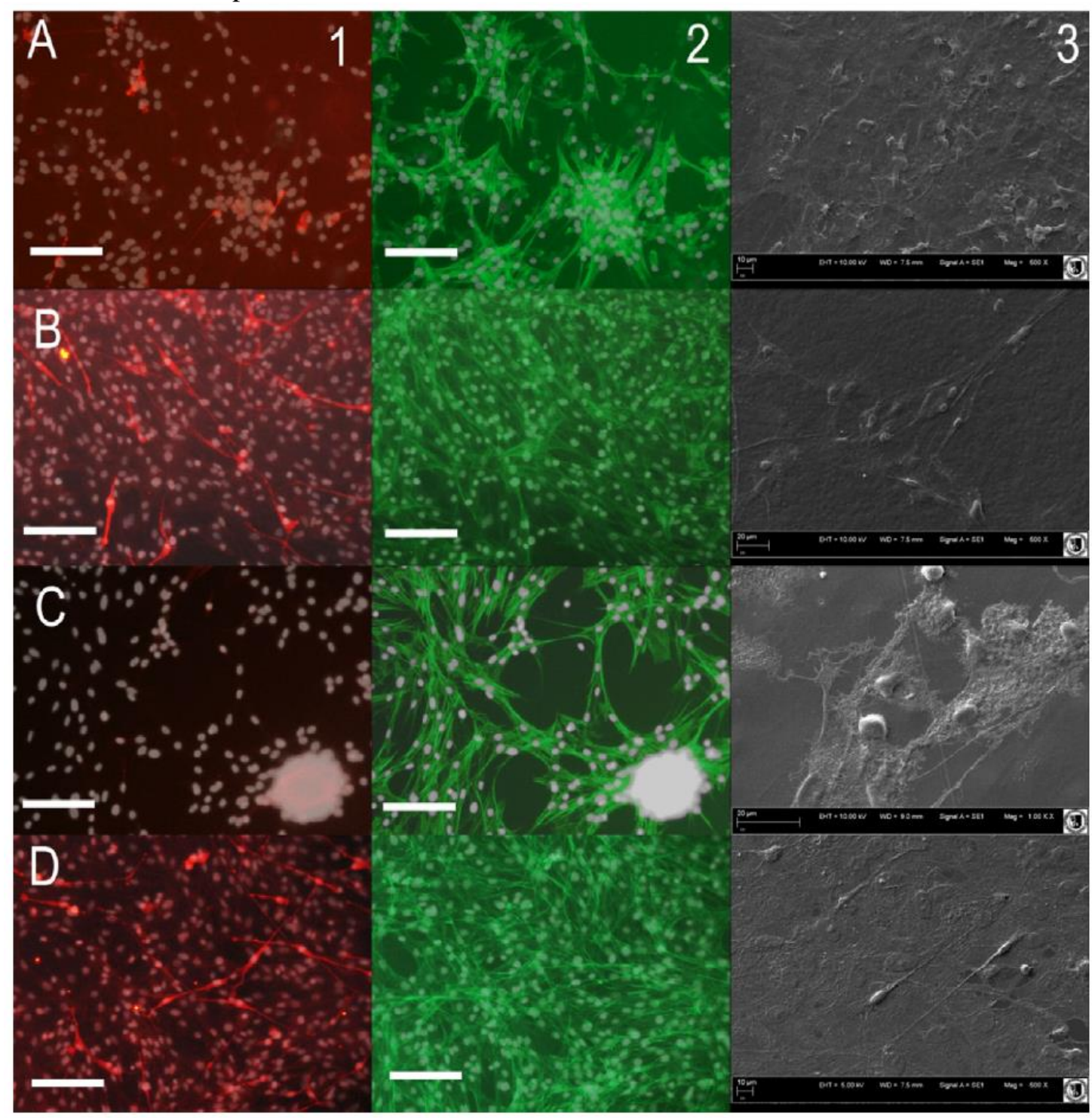

Fig. 7. Olfactory bulb glial cells (after 7 days) on PU (row A), PU/PLA blend (B), pure PLA (C) and polystyrene control (D); dyes: red + white (p75 + nuclear, respectively, column 1), green + white (actin + nuclear, respectively, 2$)$ and SEM (3); scale bars $=200 \mu \mathrm{m}^{.71}$ 


\section{Concluding remarks}

PUs are an exciting class of polymeric materials that exhibit a variety of properties that make them desirable for use as coatings and bulk materials in numerous applications in the biomedical sector. Examples include antibacterial surfaces and catheters, drug delivery vehicles, stents, surgical dressings/PSAs, tissue engineering scaffolds and electrospinning, nerve generation, cardiac patches and PU coatings for breast implants. This review has concentrated on recent literature from 2014; for earlier biomedical application of polymer coatings studies, readers are directed to a previous review in this journal. ${ }^{81}$

\section{Disclosure statement}

No potential conflict of interest was reported by the authors.

\section{ORCiD}

J. Joseph http://orcid.org/0000-0001-7036-3550

J. R. Smith http://orcid.org/0000-0001-8805-3788

\section{References}

1. O. Bayer: Angew. Chem., 1947, 59, 257-272.

2. A. Cornille, R. Auvergne, O. Figovsky, B. Boutevin and S. Caillol: Eur. Polym. J., 2017, 87, 535552.

3. Europur.org.uk Polyurethanes in Polyurethanes timeline [internet]. ISOPA: Polyurethanes 2016 [Cited 201630 Oct]. Available from: http://www.polyurethanes.org/en/what-is-it/timeline

4. H.J. Jeong and B.K. Kim: React. Funct. Chem., 2017, 116, 92-100.

5. Polyurethane paint for a durable and high-gloss finish [Internet]. 2018 [accessed 1 Mar 2018]. Available at http://www.coating.co.uk/polyurethane-paint/

6. Polyurethane paint Singapore [Internet]. Coatings.com.sg. 2018 [accessed 1 Mar 2018]. Available at http://www.coatings.com.sg/polyurethane-paint-singapore

7. Automotive interior coating Singapore [Internet]. Coatings.com.sg.2018 [accessed 1 Mar 2018]. Available at http://www.coatings.com.sg/automotive-interior-coating-singapore/

8. A. T. Chen and R. T. Wojcik: Metal Finish., 2010, 108, (11-12), 108-121.

9. Improved coating lifespan for bakeries [Internet]. Impreglon UK Ltd, Tamworth, UK. 2018 [accessed 1 Mar 2018]. Available at https://www.impreglon.co.uk/case-studies/bakeries/

10. Keeping PUR glue at bay [Internet]. Impreglon UK Ltd, Tamworth, UK. 2018 [accessed 1 Mar 2018]. Available at https://www.impreglon.co.uk/case-studies/keeping-pur-glue-bay/

11. Z. Makama, I. Doble, D. Nicolson, M. E. Webb and J. R. Smith: J. Adhes. Sci. Technol., 2017, 31, (4), 430-449.

12. J. Joseph and J. R. Smith, Trans. IMF, 2017, 95, (5), 239-240.

13. Polyurethane coatings [Internet]. ICA Group, Civitanova Marche (Macerata), Italy. 2018 [accessed 1 Mar 2018]. Available at http://www.icaspa.com/ww/en/polyurethane_coatings

14. Polyurethane coatings for metal surfaces [Internet]. Metal Coatings Corp., PO Box 630407, Houston, TX, USA. 2018 [accessed 1 Mar 2018]. Available at https://www.metcoat.com/polyurethanecoatings.htm

15. R.J. Zdrahala and I.J. Zdrahala: J. Biomat. Appl., 1999, 14, 67-90.

16. J.W. Boretos and W.S. Pierce: Science, 1967, 158, 1481-1482.

17. J.M. Buist and A. Lowe: Ann. Occup. Hyg., 1965, 8, 143-162.

18. E. Sharmin and F. Zafar: Polyurethane: An introduction, INTEC Open Science, 2012, https://www.intechopen.com/books/polyurethane/polyurethane-an-introduction, doi: 10.5772/51663

19. G. Wypych: Handbook of Polymers, $2^{\text {nd }}$ Edition, 2016, ChemTec Publishing, Ontario, Canada, ISBN: 9781895198928

20. J.X. Jiang, Y.C. Fu, Q.H. Zhang, X.L. Zhan and F.Q. Chen: Appl. Surface Sci., 2017, 412, 1-9. 
21. K. Frisch: Rubber Chem. Technol., 1972, 45, (5), 1442-1466.

22. X. Zhou, Y. Li, C.Q. Fang, S.J. Li, Y.L. Cheng, W.Q. Lei and X.J. Meng: J. Mater. Sci. Technol., 2015, 31, (7), 708-722.

23. Y. Guo, R. Zhang, Q. Xiao, H. Guo, Z. Wang, X. Li, J. Chen and Jin Zhu: Polymer, 2018, 138, 242-254.

24. A.L. Silva and J.C. Bordado: Catalysis Rev., 2004, 46, (1), 31-51.

25. P. Helmut and B.W. Von: Method of preparing polyurethane with a delayed action catalyst. Google Patents: 1964.

26. Directive 2011/65/EU of the European Parliament and of the Council of 8 June 2011 on the restriction of the use of certain hazardous substances in electrical and electronic equipment. 2011.

27. Regulation (EC) No 1907/2006 on the Registration, Evaluation, Authorisation and Restriction of Chemicals (REACH) and setting up a European Chemicals Agency. 2006.

28. R.N. Jana and H. Bhunia: High Performance Polym., 2010, 22, (1), 3-15.

29. M. Szycher: Szycher's Handbook of Polyurethanes. 1999, CRC press, Boca Raton, FL, USA.

30. A. Nakkabi, M. Sadiki, M. Fahim, N. Ittobane, I. S. Koraichi, H. Barkai and S. El Abed: Int. J. Environ. Res., 2015, 9, (1), 157-162.

31. A. Kausar: Polymer-Plastics Technol. Eng., 2017, 56, (6), 606-616.

32. M. Tausif, A. Pliakas, T. O’Haire, P. Goswami and S. J. Russell: Materials, 2017, 10, (6), 618.

33. O. S. H. Santos, M. C. da Silva and M. I. Yoshida: J. Appl. Polym. Sci., 2017, 134, (41), 45409.

34. P. Krol: Progr. Mater. Sci., 2007, 52, (6), 915-1015.

35. Polyurethanes.org. Polyurethanes in Polyurethanes applications you would not have thought of [Internet]. ISOPA: Polyurethanes 2016 [accessed 2 Nov 2016]. Available at http://www.polyurethanes.org/blog/2011/08/10-polyurethane-applications/

36. B.R. Barrioni, S.M. de Carvalho, R.L. Orefice, A.A.R. de Oliveira and M.d.M. Pereira: Mater. Sci. Eng. C, Mater. Biol. Appl., 2015, 52, 22-30.

37. S. Kumar, V. Deepak, M. Kumari and P.K. Dutta: Int. J. Biol. Macromol., 2016, 84, 349-353.

38. F. Kara, E.A. Aksoy, Z. Yuksekdag, S. Aksoy and N. Hasirci: Appl. Surface Sci., 2015, 357, $1692-1702$.

39. Y. Savelyev, A. Gonchar, B. Movchan, A. Gornostay, S. Vozianov, A. Rudenko, R. Rozhnova and T. Travinskay: Mater. Today: Proceedings, 2017, 4, 87-94.

40. S. Zanini, A. Polissi, E.A. Maccagni, E.C. Dell'Orto, C. Liberatore and C. Riccardi: J. Colloid Interface Sci., 2015, 451, 78-84.

41. P. Singha, J. Locklin and H. Handa: Acta Biomater., 2017, 50, 20-40.

42. P.J. Nowatzki, R.R. Koepsel, P. Stoodley, K. Min, A. Harper, H. Murata, J.

Donfack, E.R. Hortelano, G.D. Ehrlich and A.J. Russell: Acta Biomater., 2012, 8, (5), 1869-1880.

43. X. Sun, Z. Cao, N. Porteous and Y. Sun: Acta Biomater., 2012, 8, (4), 1498-1506.

44. W. Chen, J. Clauser, A.L. Thiebes, D.J. McGrath, N. Kelly, M.J. van Steenbergen, S. Jockenhoevel, U. Steinseifer, P.E. McHugh, W.E. Hennink and R.J. Kok: Eur. J. Pharm. Sci., 2017, 103, 94-103.

45. A. Solanki and S. Thakore: Int. J. Biol. Macromol., 2015, 80, 683-691.

46. P. Gentile, D. Bellucci, A. Sola, C. Mattu, V. Cannillo and G. Ciardelli: J. Mech. Behav. Biomed. Mater., 2015, 44, 53-60.

47. M.D. Campiñez, E. Benito, L. Romero-Azogil, Á. Aguilar-de-Leyva, M. de Gracia García-Martín, J.A. Galbis and I. Caraballo: Eur. J. Pharm. Sci., 2017, 100, 285-295.

48. M. Shaikh, N.R. Choudhury, R. Knott, J.R. Kanwar and S. Garg: Eur. J. Pharm. Biopharm., 2016, 101, 82-89.

49. C.V. da Silva, V.J. Pereira, P.T.V. Rosa, E.C.M. Cabral-Albuquerque, S.A.B. Vieira de Melo, G.M.N. Costa, A.M.A. Dias, H.C. de Sousa and M.E.M. Bragac: J. Supercritical Fluids, 2016, 115, $1-9$.

50. A.R. Unnithan, A.R.K. Sasikala, P. Murugesan, M. Gurusamy, D. Wu, C.H. Park and C.S. Kim: Int. J. Biol. Macromol., 2015, 77, 1-8.

51. L.E. Aguilar, A.R. Unnithan, A. Amarjargal, A.P. Tiwari, S.T. Hong, C.H. Park and C.S. Kim: Int. J. Pharm., 2015, 478, 1-8.

52. F. Pardini, P. Faccia and J. Amalvy: J. Drug Delivery Sci. Technol., 2015, 30, 199-208.

53. D.K. Patel, D. Rana, V.K. Aswal, S. Srivastava, P. Roy and P. Maiti: Polymer, 2015, 65, 183-192. 
54. M.N. Ali and I.U. Rehman: J. Manufact. Sys., 2015, 37, 375-395.

55. L.E. Aguilar, A. GhavamiNejad, C.H. Park and C.S. Kim: Nanomed. Nanotechnol. Biol. Med., $2017, \mathbf{1 3}, 527-538$.

56. M. Gultekinoglu, B. Kurum, S. Karahan, D. Kart, M. Sagiroglu, N. Ertas, A.H. Ozen and K. Ulbubayram: Mater. Sci. Eng. C, 2017, 71, 1166-1174.

57. C.D. Mario, I.D. Kilic, J.S.M. Yeh, M. Pighi, R. Serdoz, M.A. Gatzoulis and K. Dimopoulos: Int. J. Cardiol., 2015, 184, 664-666.

58. A.K. Singh, D.S. Mehra, U.K. Niyogi, S. Sabharwal and G. Singh: Radiation Phys. Chem., 2014, 103, 75-83.

59. E.-H. Song, S.H. Jeong, J.-U. Park, S. Kim, H.-E. Kim and J. Song: Mater. Sci. Eng. C, doi: 10.1016/j.msec.2017.05.041

60. P.I. Morgado, A. Aguiar-Ricardo and I.J. Correia: J. Membrane Sci., 2015, 490, 139-151.

61. J.I. Kim, H.R. Pant, H.-J. Sim, K.M. Lee and C.S. Kim: Mater. Sci. Eng. C, 2014, 44, 52-57.

62. J. Cheng, Y. Jun, J. Qin and S.-H. Lee: Biomaterials, 2017, 114, 121-143.

63. R.B. Trinca, G.A. Abraham and M.I. Felisberti: Mater. Sci. Eng. C, 2015, 56, 511-517.

64. H. Janik and M. Marzec: Mater. Sci. Eng., 2015, 48, 586-591.

65. E. Tomecka, M. Wojasinski, E. Jastrzebska, M. Chudy, T. Ciach and Z. Brzozka: Mater. Sci. Eng. $C, 2017,75,305-316$.

66. M. Shahrousvand, M.S. Hoseinian, M. Ghollasi, A. Karbalaeimahdi, A. Salimi and F.A. Tabar: Mater. Sci. Eng. C, 2017, 74, 556-567.

67. J. Kucinska-Lipka, I. Gubanska, M. Strankowski, H. Cieśliński, N. Filipowicz and H. Janik: Mater. Sci. Eng. C, 2017, 75, 671-681.

68. M. Marzec, J. Kucińska-Lipka, I. Kalaszczyńska and H. Janik: Mater. Sci. Eng. C, 2017, 80, 736747.

69. S.A. Guelcher, A. Srinivasan, J.E. Dumas, J.E. Didier, S. McBride and J.O. Hollinger: Biomaterials 2008, 29, 1762-1775.

70. Y. Wu, L. Wang, B. Guo, Y. Shao and P.X. Ma: Biomaterials, 2016, 87, 18-31.

71. J. Grzesiak, K. Marycz, D. Szarek, P. Bednarz and J. Laska: Mater. Sci. Eng. C, 2015, 52, $163-$ 170.

72. F.-Y. Hsieh, H.-H. Lin and S.-h. Hsu: Biomaterials, 2015, 71, 48-57.

73. Y. Ganji, Q. Li, E.S. Quabius, M. Böttner, C. Seuber-Unkel and M. Kasra: Mater. Sci. Eng. C, 2016, 59, 10-18.

74. A. D'Amore, T. Yoshizumi, S.K. Luketich, M.T. Wolf, X. Gu, M. Cammarata and R. Hoff: Biomaterials, 2016, 107, 1-14.

75. F.E. Barone, L. Perry, T. Keller and P.G. Maxwell: Plastic Reconstr. Surg., 1992, 90, (1), 77-86.

76. N. Handel, M.J. Silverstein, J.A. Jensen, A. Collins and K. Zierk: Plastic Reconstr. Surg., 1991, 88, (3), 475-481.

77. G. Vazquez and A. Pellon: Aesthetic Plast. Surg., 2007, 31, (4), 330-336.

78. K.G. Brand: Clin. Plastic Surg., 1988, 15, (4), 533-539.

79. C.M. Chen S.J. Cano, A.F. Klassen, T. King, C. McCarthy, P.G. Cordeiro, M. Morrow and A.L. Pusic: Breast J., 2010, 16, (6), 587-597.

80. P.J. Duxbury and J.R. Harvey: J. Plastic Reconstruct. Aesthetic Surg., 2016, 69, 452-460.

81. J. R. Smith and D. A. Lamprou: Trans. IMF, 2014, 92, (1), 9-19. 